\title{
The ultrasonographic correlates of carpal tunnel syndrome in patients with normal electrodiagnostic tests
}

\section{Correlazioni ecografiche nella sindrome del tunnel carpale nei pazienti con test elettrodiagnostici negativi}

\author{
M. Rahmani ${ }^{1}$ A.R. Ghasemi Esfe ${ }^{1} \cdot$ S.M. Vaziri-Bozorg ${ }^{1} \cdot$ M. Mazloumi $^{1}$ • O. Khalilzadeh ${ }^{1}$ \\ H. Kahnouji ${ }^{2}$
}

\author{
${ }^{1}$ Advanced Diagnostic and Interventional Radiology Research Center (ADIR), Imaging Medical Center, Imam Hospital, Tehran \\ University of Medical Sciences, Tehran 14155-7146, Iran \\ ${ }^{2}$ Department of Neurology, Imam Hospital, Tehran University of Medical Sciences, P.O. Box 13145-784, Tehran, Iran \\ Correspondence to: A.R. Ghasemi Esfe, Tel.: +98-216-1192670, Fax: +98-216-6910201, e-mail: areza.ghasemi@gmail.com
}

(C) Springer-Verlag 2011

Erratum to: La radiol med (2011) 116:489-496

DOI 10.1007/s11547-011-0632-6

The original version of this article, unfortunately, contained a mistake. The name of the third author should have been S.M. Vaziri-Bozorg instead of S.M. Bozorg. 